\title{
DEVELOPMENT OF EXTERNAL CONTROL BASED ON THE AVIDIN GENE OF BIRDS FOR POLYMERASE CHAIN REACTION IN REAL TIME
}

\author{
Tolstikh N.A., Candidate of Biological Sciences \\ Yushkov Y.G., Doctor of Agricultural Sciences \\ Gordov V.S., Candidate of Biological Sciences \\ Leonov S.V., Senior Researcher \\ Siberian Federal Scientific Center of Agrobiotechnologies of the Russian Academy \\ of Sciences, Novosibirsk, Russia \\ Kashapova S.V. ${ }^{*}$, Candidate of Veterinary Sciences \\ Novosibirsk State Agrarian University, Novosibirsk, Russia \\ *E-mail: setochka07@mail.ru
}

\begin{abstract}
Intensive development of poultry farming is directly connected with the development of new methods of diagnosing diseases. One of these methods, allowing an accurate diagnosis in a short time, is a polymerase chain reaction. The basic principles of PCR are firmly established in the daily practice of research and clinical laboratories. This article presents the results of the development of external control for polymerase chain reaction in real time for the diagnosis of bird diseases. The reaction has specificity and a sensitivity of 200 copies per $\mathrm{ml}$. The calibration graph is used to estimate the number of birds' genome per reaction.
\end{abstract}

\section{KEY WORDS}

Polymerase chain reaction, real time, gene, avidin, infection, biomaterial, bird, primers.

During recent years, more and more molecular-biological methods find use in agriculture, especially in veterinary medicine. One of such methods is -Polymerase Chain Reaction (PCR), allowing to accumulate section of deoxyribonucleic acid (DNA) inside of a test tube in almost unlimited quantities $[9,13,14]$. Basic principles of polymerase chain reaction for the detection of DNA was proposed by Kleppe and co-authors in 1971 [5]. Currently, polymerase chain reaction (PCR) is the "gold standard" in the diagnosis of many viral and bacterial infections of human beings and animals. Register the result of the PCR is possible at the end of the reaction («endpoint»), or throughout the reaction («real-time»)[15, 3, 4, 2, 10]. In the early 90 s of last century, the researchers proposed to register the accumulation of DNA during PCR $[11,12]$. Registration of the reaction product in «real time» helps to determine not only the presence/absence of DNA/RNA pathogen in the sample of biological material, but also to determine its concentration. The obtained data can provide high value of the flow of epidemic process in the population, and also play an important role in study of the infectious process.

The main problem for quantitative analysis by PCR «in real time» is the standardization of methods of selection of the material $[20,1,7,19]$. For detecting quantities of DNA causative agent of infectious disease in scrapes, of blood or other body fluids, it is sufficient to use a standardized intake method of the biomaterial, and the same methods of DNA extraction $[6,16]$. Working with samples of organs or tissues, it is impossible to create a standardized method of sampling of biological material because they have different structure and density, respectively a different number of cells. In this case, quantification of the DNA matrix of the infectious agent is conducted in relation with the number of the reference matrix, which is often presented by the DNA of the host, so-called «external control». To quantify an infectious agent is used the ratio of the number of DNA of external control to the amount of DNA of the infectious agent. Once selected conditions of "real-time» quantitative PCR execution for determination of the external control, it is possible to use this reaction with all reactions, aimed 
at the quantitative detection of DNA infectious agents in the biomaterial. Problems listed in the introduction led to the goals and objectives of the study.

Goal of study is to develop an external control for quantifying DNA infectious agents of birds for polymerase chain reaction «in real time».

To achieve the goal, were formulated following tasks: selection a target for the development of the external standard PCR «in real time»; selection of specific oligonucleotide primers; testing of the temperature modes of PCR «in real time».

\section{METHODS OF RESEARCH}

Material for choice of the target was the sequence of the gene which is coding a protein of the avidin, deposited on the website http://www.ncbi.nlm.nih.gov.

The spleens of broiler chickens were exposed to the DNA isolation and subsequent «real-time» PCR. For the selection of the sequences of the primers was used the software «Primer Premier 5.0» and «DNAstar». For the detection of the external control was chosen the method of interaction of double-stranded DNA with the intercalating dye SYBR Green as the most common and affordable.

\section{RESULTS AND DISCUSSION}

The normalization of the results of the polymerase chain reaction is necessary in order to correct the variation between the samples. The starting material obtained from various sources usually differs in weight, number of cells, preservation, and amount of DNA. The ideal gene for normalization should be expressed at the same level in all cells of the body, regardless of the conditions. $[17,18]$. Such properties are possessed by the gene of avidin.

For the development of external controls for quantitative PCR diagnostics of pathogens of birds' diseases was chosen the avidin gene. The nucleotide sequence of the avidin gene consists of 1133 base pairs.

Based on the analysis of the genome were selected following primers: direct 5'TGCAGTGCTCGCTGACTGGG-3' complementary sequence at position 173 - 192 BP; reverse 5'-AGGTGGGCTGGCAGGCTCT-3' complementary sequence at position $334-352$ BP PCR was carried out on a fragment at position 173-352п.N. 5'Tgcagtgctcgctgactgggaaatggaccaacaacctgggctccatcatgaccatcagggctgtgaacagcagaggtgaattc gcaggcacctacctcacagctgtagcagataatccaggaaacatcaagctatcaccactgcttgggatccaacacaaaagagcct gccagcccacc3'.

Components of the reaction to study single DNA sample: $10 \times$ buffer $\mathrm{pH}$ of 8.8 and 2.5 ál; dNTPs $(0.5 \mathrm{~mm}$ each) and $2.5 \mu \mathrm{l}$; a mixture of primers $(10 \mathrm{~mm}$ each) $-0.3 \mu \mathrm{l}$; autoclaved bidistilled water and $5.0 \mu \mathrm{l}$; Taq polymerase at a concentration of $5000 \mathrm{u} / \mathrm{ml}$ at a dilution of $1: 16$ a 0.5 ál; SYBR Green (1:250) and $0.25 \mu \mathrm{l}$.

The reaction was performed in a real-time amplifier using the software.

In the first phase of the work needed to build a specific amplicon and to identify its melting temperature. Evaluation of reaction was carried out based on the schedules, reflecting the synthesis of amplicon and its quality. Data analysis was performed using melting curve. At the end of the PCR the tube was slowly heated from 54 to $95^{\circ} \mathrm{C}$, simultaneously recording the change in fluorescence. For the developed reaction it is equal to $86^{\circ} \mathrm{C}$.

The next step was to establish the optimal annealing temperature. For this, we carried out the reaction in the temperature gradient in the range of $63.3-54.1^{\circ} \mathrm{C}$. The optimal primer annealing temperature was $58^{\circ} \mathrm{C}$.

To determine the number of genome equivalents in a PCR product, we used the conversion of known concentrations of DNA with a known sequence in molar concentration. For this, we carried out the electrophoresis obtained in the course of PCR products in $6 \%$ polyacrylamide gel. From the gel were cut out the phase, which contained DNA relevant to the calculated length and the extraction of the fragment. In the fluid obtained after selection was determined DNA concentration on the spectrophotometer, using the reagent kit HS DNA according to the Protocol. The conversion of the concentrated DNA into the molar 
concentration was conducted using the program «Conversion: weight - moles (for Nucl. acid)» (http://molbiol.ru/scripts/01_07.html). Through a series of tenfold dilutions of PCR product with known molar concentration, were received samples used as calibrators. The analytical sensitivity of the reaction was 200 copies of DNA avidin birds in $1 \mathrm{ml}$, which corresponds to the 31 threshold cycle in PCR «in real time».

To study the specificity of the reaction were used human, dog, cat, pigeon, chicken and pig DNA samples. A positive result was detected in samples from pigeons and chickens. Thus, the developed reaction is specific.

To quantify external control of PCR «in real time» we developed the calibration curve (Figure 1).

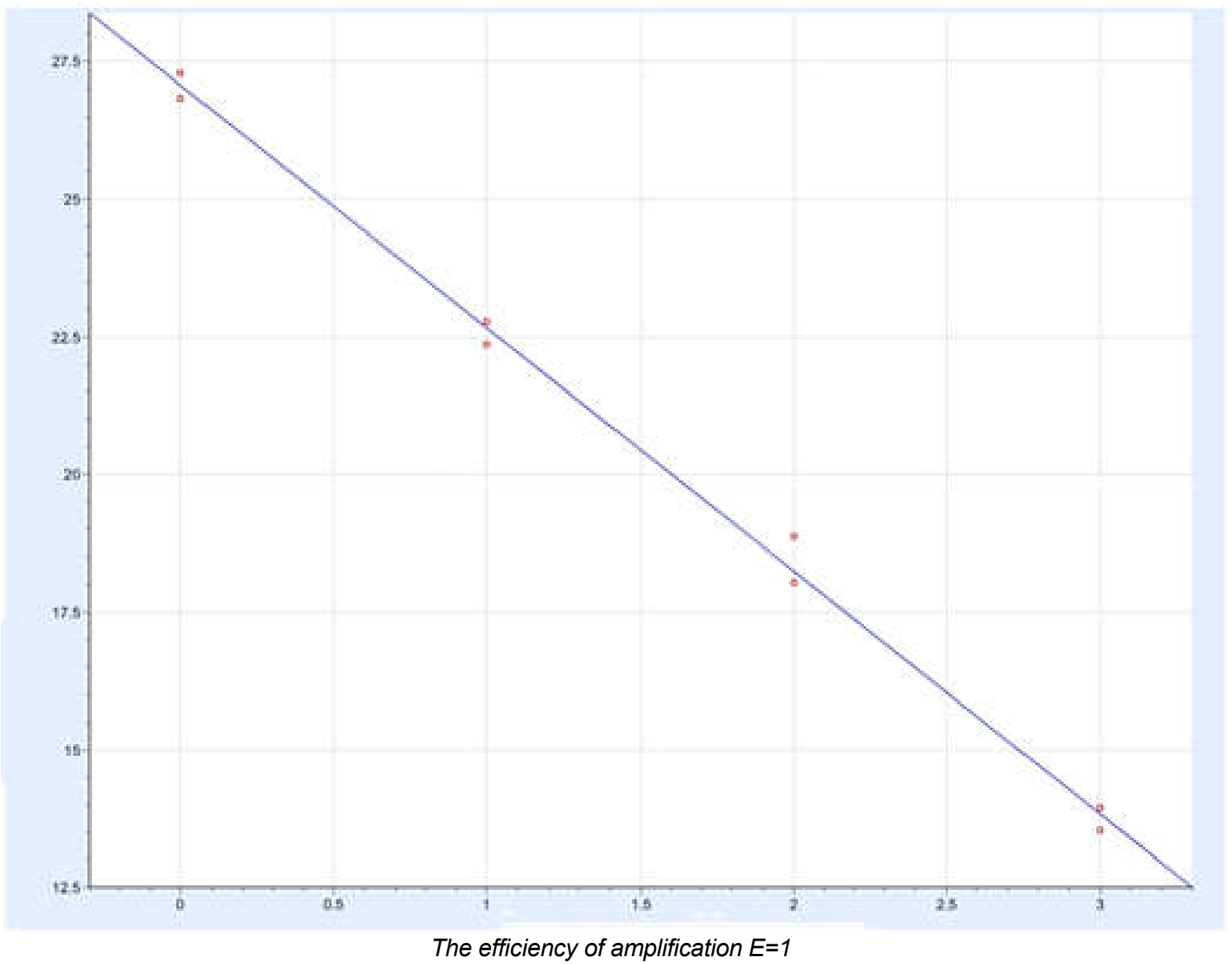

Figure 1 - Calibration chart for determination of avidin concentration

Evaluating the calibration curve, efficiency of the reaction is quite important, for each batch of reactions it must be $100 \%(E=1)$. Small differences in the efficiency of the reaction lead to significant differences of results obtained during PCR [15].

The obtained calibration graph allows determining the concentration of avidin in the cells and tissues of the poultry organism.

\section{CONCLUSION}

The avidin gene of birds was chosen as the target for the development of external PCR control «in real time». It is present in all cells of the body of the bird and is expressed in the same amount. To perform this reaction, primers flanking the avidin gene sequence of birds at position 173-352 bp were chosen. The optimum annealing temperature of the impurities was $58^{\circ} \mathrm{C}$. By means of the developed «real time» PCR on the avidin gene of birds, which is 
taken as the external control, it is possible to estimate the copy number of the genome of birds. The reaction is specific; its sensitivity is 200 copies of DNA avidin of birds in $1 \mathrm{ml}$.

\section{REFERENCES}

1. Annoscia, G. A new PCR assay for the detection and differentiation of Babesia canis and Babesia vogeli / G. Annoscia [ et al.] // Ticks and Tick-borne Diseases. - 2017. - №17. www.ncbi.nlm.nih.gov/pubmed/28739301

2. Arezi, B. Amplification efficincy of termostsble DNA polymerases / B. Arezi [ et al.] // Analitical biochemistry. - 2003. - №321. - P. 226-235.

3. Atallah, Z. K. Multiplex real-time quantitative PCR to detect and quantify Verti-cillium dahliae colonization in potato lines that differ in response to Verticillium wilt / Atallah, $Z$. K. [ et al.] // Phytopathology. - 2007. -№97. - P.865-872.

4. Bates, J. A. The application of real-time PCR to the identification, detection and quantification of Pyrenophora species in barley seed / Bates, J. A. [ et al.] //Mol. Plant Pathol.- 2001. - №2. - P.49-57.

5. Borsu, L. Clinical Application of Picodroplet Digital PCR Technology for Rapid Detection of EGFR T790M in Next-Generation Sequencing Libraries and DNA from Limited Tumor Samples/ L. Borsu [et al.] // J Mol Diagn. - 2016. - №18(6). - P.903-911.

6. Chiu, C.H. Clinical characteristics and treatment outcomes of lung adenocarcino-mas with discrepant EGFR mutation testing results derived from PCR-direct se-quencing and real-time PCR-based assays / C.H. Chiu // J Thorac Oncol. - 2014. -№9(1). - P.91-6.

7. Denis, J.A. Droplet digital PCR of circulating tumor cells from colorectal cancer patients can predict KRAS mutations before surgery // Mol Oncol. - 2016. -№10(8). P.1221-31

8. Glynn, N. C. Evaluation of PCR assays for quantifying seed-borne infection by Fusarium and Microdochium seedling blight pathogens // J. Appl. Micr. - 2010. - №108. - P.81-87.

9. Graaf, A. Real-time reverse transcription PCR-baced sequencing-independent pathotyping of Eurasian avian influenza A viruses of subtype H7 // Virol J. - 2017. - №14

10. Gudmestad, N. C. A real-time PCR assay for the detection of Clavibacter michi-ganensis subsp. sepedonicus based on the cellulase A gene sequence/ N. C Gud-mestad // Plant Dis. - 2009. - №93. - P.649-659.

11. Higuchi, R. Kinetic PCR analysis: Real-time monitoring of DNA amplification reaction / R. Higuchi [ et al.] // Biotechnology. - 1993. - №11. - P. 1026-1030.

12. Higuchi, R. Simultaneous amplification and detection of specific DNA sequences / R. Higuchi [ et al.] // Biotechnology. - 1992. - №10(4). - P. 413-417.

13. Lee, KY Predictors of mortality in autoimmune disease patients with concurrent cytomegalovirus infections detected by quantitative real-time PCR / K.Y. Lee [ et al.] // PLoS One. - 2017. - №7. - e0181590.

14. Medrano, G. Comprehensive selection of reference genes for quantitative RT-PCR analysis of murine extramedullary hematopoiesis during development / G. Medrano [et.al.] // PLoS One. - 2017. - №7. - e0181881

15. Real-time PCR : a textbook / D. V. Rebrikov [ et al.]; ed. by D. V. Rebrikov. - 2nd ed. Rev. and additional - M: BINOM. Knowledge laboratory, 2008. - 223 p.

16. Sarier,a M., Results of Real-time Multiplex Polymerase Chain Reaction Assay in Renal Transplant Recipients With Sterile Pyuria / M. Sarier [et.al.] //Transplantation Proceedings. - 2017. - №6. - P. 1307-1311

17. Schmittgen, T.D. Effect of experimental treatmen onhouskeeping gene expression: validation by real-time, quantitative RT-PCR / T.D. Schmittgen, B.A. Zakrajsek // J Biochem Biophys Metods. - 2000. - №46. - P. 69-81

18. Studies on polynucleutides. XCVI Repair replication of short synthetic DNA's as catalyzed DNA polymerase // Journal of Molecular Biology. - 1971. - №56. - P. 341-361.

19. Vandesomple, J. Accurate normalization of real-time quantitative RT-PCR data by geometric averaging of multiple internal control genes // Genome boil.- 2002: 3.

20. Zhang, B.O Comparison of droplet digital PCR and conventional quantitative PCR for measuring EGFR gene mutation // Exp Ther Med. - 2015. - №9. - P.1383-1388. 